\title{
ARTE E HISTÓRIA: DA CAVERNA À "CAVERNA", SEGUNDO ADORNO E WALTER BENJAMIN
}

\author{
[ History AND ART: From the CAVE to "CAVE", ACCORDing to WALTER BENJAMin AND \\ ADORNO ]
}

\begin{abstract}
Resumo: Trata-se de fazer o movimento que, partindo da atualidade e singularidade da arte, desce até o passado, pela história, e, a partir da história, segue em direção à atualidade, pela arte, acompanhando, nisto, uma orientação de Walter Benjamin retirada de um comentário de Theodor Adorno.
\end{abstract}

Palavras-chave: Arte; História; Emancipação; Indivíduo; Modernidade
Abah Andrade *

Universidade Federal da Paraíba, Brasil

\section{I}

ABSTRACT: The aim of this little essay is to try to make the movement that, starting from the actuality and singularity of art, descends to the past, through history, and, from history, goes towards the present, through art, following an orientation by Walter Benjamin withdrawn from a commentary by Theodor Adorno.

KEYwORDS: Art; History; Emancipation; Individual; Modernity

reflexão acerca das relações entre arte e história pode beneficiar-se A dessas duas passagens que, em sua Teoria estética, Theodor Adorno lega como emblemas a formar uma espécie de lufada de sentidos como um aguilhão a despertar e a convidar seu leitor a se proteger contra a inércia do pensamento dualista e estanque, nutrindo-o, com isso, com certo quinhão de senso dialético: "A arte tem o seu conceito na constelação de momentos que se transformam historicamente; fecha-se assim à definição." (Adorno, 1982, p. 12) Nessa primeira passagem, impossível deixar de considerar o seguinte: se definir é fechar o objeto em seu conceito, e o conceito da arte, que se dá em "constelação de momentos" historicamente lábeis, flexíveis e instáveis, atrela-se à história de sua formação inacabada, então seria próprio da arte furtar-se constantemente a uma definição que a fisgasse em sua essência, uma vez que o conceito de arte se deixa ver, ou, antes,

* Programa de Pós-Graduação em Filosofia da Universidade Federal da Paraíba-UFPB. m@ilto: andradesimples@gmail.com 
apenas entrever nessa sua característica íntima de não se dar à definição porque sua própria essência é história, a saber, poder de arruinamento e autotransformação no tempo.

Daí, a segunda passagem: “O momento histórico é constitutivo nas obras de arte; as obras autênticas são as que se entregam sem reservas ao conteúdo material histórico da sua época e sem a pretensão [de se colocar acima dela]. São a historiografia inconsciente de si mesma da sua época." (Id., ibid., p. 207) Ou seja, cada nova obra, ao trazer uma solução para um problema posto pela própria história da arte ou pela série das obras anteriores de um mesmo artista (Gombrich, 2009), agrega à sua singularidade, por um lado, uma criação inusitada, por outro, em sua própria novidade, uma cifra do mundo (objetivo ou subjetivo) de onde ela emergiu como algo imprevisto. O inusitado é a cifra, e é nessa cifra que se guarda a "historiografia inconsciente", que exigiria decifração para deixar vir à tona um complexo de significações e, assim, quiçá, definir a obra e a época conscientemente.

Mas, se o conceito de arte não pode ser dado de frente por uma definição, dizer que a história constitui a arte não seria oferecer, pelas costas, e de qualquer modo, uma definição? Sim e não, como sói acontecer com enunciados dialéticos, pois se é dito que a história constitui a arte, todavia não é dito o que seria a história que a constitui, uma vez que nela a história está posta, como dissemos, como uma cifra.

Dois caminhos, desse modo, se nos abrem à investigação. Primeiro aquele que vai da história à arte; segundo, o que vai da arte à história. Entre os dois, porém, suspenso na própria tensão que a simples existência de uma obra de arte singular põe e impõe, resta o presente, a atualidade, torvelinho do qual a segunda investigação parte e ao qual a primeira investigação chega.

Essa tensão do presente instaurado pela existência singular de uma obra, porém, não é uma mera imagem, mas a descrição de uma realidade muito precisa.

$\mathrm{O}$ texto de Adorno (que em muitos pontos soa como um palimpsesto de textos de Walter Benjamin) chama a essa realidade "emancipação" ou "autonomia da arte". De fato, ali onde, da arte, Benjamin disse que estava "na época da sua reprodutibilidade técnica", Adorno (1982, p. 11) escreve, como hipertexto, "na época de sua emancipação". O hipertexto de Adorno revela a anatomia da expressão benjaminiana: a técnica de reprodução libera a arte de sua dependência da religião; é a época da sua autonomia (Jimenez, 1999, p. 83), de sua emancipação como uma atividade que deixa para trás o serviço do culto religioso e traz em si mesma agora o princípio de sua inteligibilidade.

A relação entre arte e história, em qualquer dos dois movimentos de investigação antes referidos, deve começar a ser pensada nesse limiar; e esse limiar é o de Benjamin. Seu lance genial foi ter sugerido toda uma linha de pesquisa em história da arte a partir de um detalhe da arte contemporânea que reverbera sobre a totalidade da produção artística, lançando luz não só sobre o processo histórico-social e estético da arte do presente, como também luz dentro da inteligibilidade da história da arte como um todo, desde a arquitetura e a escultura até a fotografia e o cinema. Esse detalhe é a técnica, ou mais precisamente, a técnica da reprodutibilidade.

Com esta, dois pares de noções correlatas vêm à baila e se chocam dialeticamente na realidade da experiência de tensão entre religião e política: "tempo e eternidade", por um lado, e "perfeição acabada e perfectibilidade infinita", por outro. $\mathrm{O}$ eterno está para o perfeito, assim como o tempo para a perfectibilidade 
infinita; o tempo está para a política (Aristóteles já dizia: o ser humano é um animal político porquanto é perfectível <Aristóteles, 1997, p. 15>), assim como o eterno, claro, está para a religião. Mais: a obra de arte singular (logo, sem série; logo, sem tempo; logo, eterna em sua singularidade) está para a experiência religiosa, assim como sua reprodução (em série, logo, com o tempo de uma cópia para outra; logo, passageira em sua trivialidade) está para a experiência política (o mundo da cidade como um mundo, a região do mundano, portanto, do profano). O singular, como original, agrega em si a tradição de onde ele parte e de onde haure sua autenticidade. A reprodução estoura a tradição e chama a atenção para o contexto novo onde ela é possível: a grande cidade.

É essa constelação de conceitos que se move constantemente, de um ponto a outro, no texto famoso de Benjamin, como uma tentativa de abarcar a condição dúbia da autonomia contemporânea da arte. A esse respeito, que seja recordada essa passagem daquele texto benjaminiano: "O filme é, pois, a mais perfectível das obras de arte. $\mathrm{O}$ fato de que essa perfectibilidade se relaciona com a renúncia radical aos valores eternos pode ser demonstrado por uma contraprova." E, por um salto de tigre que vai do cinema à arte grega, continua: "Para os gregos, cuja arte visava a produção de valores eternos, a mais alta das artes era a menos perfectível, a escultura, cujas criações se fazem literalmente a partir de um só bloco." Seguindo imediatamente disso um novo salto para o presente: "Daí o declínio inevitável da escultura, na era da obra de arte montável" (Benjamin, 1994, p. 175s) A consideração do presente puxa o pensamento até o passado, vai da arte à história; e arranca-se desse passado em direção ao presente, vai da história à situação contemporânea da arte.

Com isso, a situação contemporânea da arte, porém, não se deixa ver satisfatoriamente com o simples apontar do dado positivo de que a arte tenha se tornado uma autônoma esfera social de valor; é preciso levar em conta também o dado negativo. "Sem dúvida", diz Adorno, "a autonomia permanece irrevogável. (...) Mas a sua autonomia começa a ostentar um momento de cegueira." (Adorno, 1982, p. 11). O negativo, que Adorno descreve como "cegueira", ausência de luz imanente ao positivo opaco, que seria a autonomia, deixa-se ver, no texto de Benjamin, como uma experiência de perda: o desembaraçar-se da arte em relação ao culto religioso é o movimento pelo qual resta evidente a perda de sua aura, o brilho invisível que recobria a peça singular de arte e a tornava, por isso, inacessível, por mais próxima que estivesse de quem a contemplava.

A aura, que criava sobre a obra um círculo intangível de proteção, uma vez destruída, deixa, na verdade, a obra desamparada: autonomia é também desamparo (Andrade, 2016, p. 137). E isto aponta, antes de tudo, não tanto para a arte, mas para a situação histórica em que a arte desponta ou emerge como "autônoma": é o momento em que, não sem ironia, também a religião perde sua centralidade na experiência de vida, e a perde para o processo de formação do Estado laico, no desenrolar de um movimento mais essencial, que é o desenvolvimento da economia capitalista burguesa, na qual, ao lado do desenvolvimento da ciência como força produtiva, a emergência do indivíduo na experiência da modernidade torna-se a um só tempo inevitável e decepcionante (Matos, 1989, p. 150). A modernidade, no que diz respeito ao indivíduo, deixa-se perceber como um tempo do desamparo vivido por ele em decorrência da dissolução das antigas formas de vida comunitária, com o subsequente destacamento, tal como a descreveu Max Weber, de esferas de valores 
que se tornam autônomas na exata medida em que ganham, a partir de seu interior, formas de racionalidade que tentam esclarecê-las e legitimá-las (Habermas, 2000, p. 24), mas no mesmo instante em que as reconhecem, por isso mesmo, como precárias, pois, do contrário, não cobrariam legitimação de si.

Como, também nesse processo, o indivíduo, que se destaca do todo social, é entregue a si mesmo sem mais o horizonte de proximidade do convívio com seus pares, convívio que anteriormente o conformava e o confortava, gostaríamos, pois, no interior dessa constelação histórico-conceitual, de fazer um paralelo entre o processo de autonomização da arte e o processo de emergência histórica do indivíduo, porque tudo indica que eles são, de fato, paralelos e entrelaçados. A pressão social que conteve a autonomização da arte, ligando esta última ao serviço do culto religioso fomentador da coesão social, não seria ela a mesma pressão que atou o espécimen humano singular ao grupo como simples membro da tribo?

Sabe-se, contudo, que essa pertença do membro à tribo resvalava em prestígio para o próprio membro, ao passo que o indivíduo das sociedades ditas modernas, ao perder o prestígio da pertença a seu grupo de origem, tem de inventar novos valores para suprir a defasagem de respeito que a experiência moderna de vida impõe. A decisão pela arte abstrata, e o fim da representação do real forçado pelo surgimento da fotografia, não poderiam ser pensados como uma forma de cobrar de volta o prestígio ao indivíduo na era de sua completa espoliação? A perda da evidência da arte na era de sua banalização não teria levado o artista, em desespero de causa, a forçar, pela representação do fim da representação, um retorno da arte à caverna? Não seria a tela um duplo da caverna, e a falta de significação do que se vê nela o escuro que protegeria do olhar profano um dublê de conteúdo mágico e sagrado nas entranhas (entrementes imperceptíveis) do quadro?

\section{II}

Arte \& modernidade - essa devia, de fato, ser a equação de toda a história da arte, desde a pré-história. Modernidade na pré-história, como assim? Onde quer que haja arte, ali também há de haver modernidade. Mas, o que seria a modernidade? A modernidade seria, em qualquer tempo, o processo pelo qual o logos (o modo como o ser humano traça sua relação com a natureza e, mediante isso, com os outros seres humanos) deixa de ser concebido como uma substância homogênea e, com isso, provoca ou é capaz de provocar uma formalização crescente segundo distintas esferas de valor decorrentes das cisões internas à própria experiência cultural onde possa haver aquela diferenciação entre o ser humano e a natureza, e entre os seres humanos entre si (Andrade, 2016). Isso significam três coisas: 1) a modernidade é menos uma época e mais um processo sempre iminente no interior da experiência do ser humano na face da terra; 2) a possibilidade de sua emergência sempre fora, em tempo, cerceada; 3) o cerceamento nunca esteve livre de oposições, as quais são responsáveis por tensões sociais dentro de uma mesma tradição cultural e por progressos e transformações nas formas de arte como nas formas de vida.

A modernidade, uma vez surgida, é a ocasião que emerge vigorosa no mesmo tempo em que entra em crise; por isso não se deve confundir, a esse respeito, "modernidade" com "tempos modernos", pois há uma modernidade na criação do bezerro de ouro, na arcaica região dos hebreus, logo contornada com o "salto no ser" 
do monoteísmo transcendente da Lei mosaica (Voegelin, 2009, p. 411); há uma modernidade no alvorecer da Grécia arcaica, que a passagem à escrita dos poemas homéricos tenta conjurar (Adorno e Horkheimer, 1985); há uma modernidade na decadência da polis grega clássica, durante a época de helenismo (Auboyeur e Aymard, 1993a); há uma modernidade na experiência histórica de Roma (Auboyeur e Aymard, 1993b); e a história do cristianismo é a história de sua ambivalência (Lebrun, 2006, p. 67) quanto à modernidade: o cristianismo é a grande defesa da dignidade humana, o momento em que Deus se faz homem, indivíduo simples e humilde; cresce no momento em que se desenvolvem hábitos que formarão o perfil do indivíduo dos "tempos modernos": a leitura silenciosa; o sentido do privado (a cela do monge); e o próprio monge como indivíduo que nega o mundo para servir unicamente a Deus (Dumont, 2000; Arriès e Duby, 2009); mas é também contemporâneo do projeto de salvação da humanidade no qual ninguém vai ao céu senão por Cristo, por seu Corpo, que é a Igreja, totalidade fechada para a qual o individualismo representa soberba, pecado, perdição.

Nasce, pois, a modernidade como a época da crise por excelência, e diz respeito ao processo de estiolamento do tecido comunitário, com a consequente possibilidade de emergir a figura, sempre evitada, mas, incontornável, do indivíduo. As obras de arte pré-históricas, como se sabe, não eram, para usarmos a terminologia de Benjamin, objeto de "exposição", mas de "culto" (Benjamin, 1994, p. 172). Produzir arte é produzir a si mesmo como indivíduo livre, como artista; mas a sociedade pré-histórica não suportaria um indivíduo livre; isso colocaria em risco o próprio futuro da espécie humana (do grupo), que precisava de coesão para protegerse contra os inimigos naturais e sobrenaturais. Como, então, dar vazão a essa necessidade natural do ser humano, que Aristóteles designaria como o pôr-se a caminho de fazer como a natureza, a "imitação" (mímesis), que seria o princípio da arte, sem contudo estragar a unidade do corpo social? Era preciso levar os indivíduos mais tendentes a essa inclinação natural para o mais fundo dos fundos da caverna. Estranhos "indivíduos", esses, que tão próximos chegavam da natureza por seu poder de fazer como a natureza fazia. E era preciso lhes dar uma missão, já que não se podia dar-se ao luxo de prescindir deles: a obra de sua arte tornava-se, então, sujeito de magia, portadora de poderes úteis à tribo e à sua tarefa de manter-se em vida, seja materialmente, pelo sucesso das caçadas; seja espiritualmente, pela ordem interna na correlação de suas partes, conquanto a arte se pusesse como suporte do mito. Quanto ao artista, mago entusiasmado ou marginal recuperado para o bem da comunidade, nada se pode dizer mais do que aquilo com que concordam os historiadores: que a arte pré-histórica permaneceu ligada a ritos que a ligavam estritamente à dimensão religiosa. Não se conhece nenhum Van-Gogh pré-histórico.

Os mitos homéricos, como obras de arte da literatura oral, vararam os séculos alimentando espiritualmente um povo onde a tendência para a individuação era enorme. $\mathrm{O}$ que diziam esses mitos, entrementes? Que não se pode desobedecer às ordens divinas impunemente. Se Agamêmnon era Rei, isso era uma determinação de Zeus. Desobedecer suas ordens era desobedecer a Zeus. Com quem devia ficar Briseida, se ela nada tinha a ver com devolver ao pai a filha do Sacerdote de Apolo? Aquiles já a tinha como sua. Dava mostras de parecer um ser humano dono de um querer individualizado, pronto a confrontar-se com um Rei. E o próprio rei tomava a decisão em favor de seu gosto "pessoal", afrontando a vontade do velho pai daquela outra moça, que implorava sua devolução em nome de Apolo. A continuação da 
estória mostraria que somente esse velho pai, sacerdote de Apolo, estava certo, pois o certo é seguir as ordenações do deus, e não seu próprio capricho. Adorno e Horkheimer, na Dialética do esclarecimento, sugerem que somente quando o processo de individuação ameaçava tornar-se incontornável foi que os gregos sentiram a necessidade de compor os mitos em uma narrativa escrita unitária. A epopeia seria a obra de organizar mitos que já perdiam seus efeitos de coesão social, a fim de manter uma educação nos trilhos daqueles valores que se esgarçavam mais e mais com o tempo: os valores da ordem.

A tensão gerada pela possibilidade de surgimento do indivíduo foi resolvida pela epopeia durante uns três séculos, até nova crise. Esta nova crise se deixa ver nos chamados pensadores "pré-socráticos". Conta-se que a filosofia teria nascido por essa época. Notemos, todavia, que as obras desses pensadores eram, sobretudo, poemas. A poesia lírica teria logo em seguida sua época de ouro. Mas seriam as tragédias e as comédias que procurariam competir com a filosofia no sentido de dar uma solução concreta para o problema da desordem social causada pela prevalência crescente do indivíduo sobre o todo. Essa prevalência se deixa documentar pelo movimento sofístico. Mas a obra de Platão conseguiria suplantar os sofistas e apresentar uma solução alternativa àquela preconizada, via sentimentos e emoções, pela arte dramática e sua proposta de catarse: a solução platônica, racional, em oposição à catarse trágica, sentimental, seria a própria dialética. Poder-se-ia dizer, nesta altura, que seria a vitória de Apolo contra Dioniso. Com efeito, e em verdade, enquanto Platão escrevia sua obra, era a escultura quem se mantinha vitoriosa, unindo em si, ao mesmo tempo, o particular do corpo humano e o universal da referência divina, ao mesmo tempo em que, bela arte, mantinha-se peça de adoração religiosa.

A Grécia clássica, berço do individualismo, não era menos o berço da mais bela experiência comunitária de todos os tempos: a democracia, aliás contestada por Platão. Fídias e Péricles são os verdadeiros destaques dessa conexão entre arte e história (política) deste momento. Alexandre Magno, ao alargar os horizontes políticos e geográficos dos gregos (helenos), levou a cultura helênica a lugares imprevistos. A helenização do mundo, porém, principalmente depois da morte de Alexandre, implicou a dissolução da polis. A cidade agora era Roma, cujo cultivo da arte, todavia, era, sobretudo, sua recepção, seu consumo, primeiro, da arte dos etruscos, depois, do que os gregos produziam. Artistas sem pátria, escravos em terra estrangeira, os gregos já não encontravam na religião clássica o amparo para seus anelos mais íntimos, e a abertura para novas formas de religiosidade estava a caminho. "No culto da Fortuna reconhecemos, sem dificuldade, o desejo unânime de garantir a felicidade para si mesmo, graças à proteção de forças superiores. A inquietude dilacerava as almas, e os homens procuravam ansiosamente a salvação." (Auboyeur e Aymard, 1993a, p. 400) Menos de duzentos anos depois de estabelecido esse clima de "consciência infeliz", um certo fariseu, de cidadania romana, tendo se convertido a uma nova seita religiosa vinda do Oriente, iria oferecer abundante consolo a essas almas solitárias de todo mundo: Paulo de Tarso.

As formas de vida vividas sob o Cristianismo tornam-se, de novo, comunitárias. Como se sabe (Marramao, 1995), os elementos estruturantes da cultura medieval eram a ordem e a regra (ordo et regula). Vivendo sob a estreita fidelidade a esses elementos, os medievais se confinavam submissos à tradição (traditio) e à autoridade (auctoritas), agindo sempre em conformidade com os seus 
ditames. A autoridade, forma de poder veiculada pela tradição (também afinal outra forma de poder), exercia sua força sobre os súditos como uma potência exterior ( $a b$ extrinseco), ministrando-lhes normas reguladoras de seus comportamentos $\mathrm{e}$ maneiras de pensar, promovendo-se assim como vetor de suas formas de vida. Os súditos eram, antes de tudo, membros da comunidade, isto é, como o próprio nome indica: suas vidas não faziam sentido senão enquanto participavam de uma comunidade (Legoff, 2005, p. 290). Porém, se, por um lado, a comunidade lhes cerceava os movimentos de suas vidas (como diríamos hoje, em retrospectiva), por outro lado fornecia-lhes prestígio e lhes resguardava de qualquer crise ou conflito de consciência, pois lhes estava à mão todo um padrão de comportamento preestabelecido capaz de orientar a conduta.

$\mathrm{Na}$ verdade, dizer que os medievais poderiam sofrer algo como uma "crise de consciência" não é nem mesmo apropriado; seria cometer anacronismo, e de fato essa situação se arrasta por todo o Ancien régime, em meio ao processo de fermentação da ascensão burguesa. Em Le Cid, de Corneille (2012), Rodrigo não hesita em assassinar o futuro sogro para limpar a honra do pai, mesmo correndo o risco de perder a mulher de sua vida, pois sabia que sua existência e a possibilidade mesma de amar uma mulher estavam subordinadas ao dever para com o pai, que o gerara e lhe dera uma família, somente no interior da qual ele permanecia alguém digno de amar e ser amado. Qualquer deslize entre uma ação e sua norma se resolvia em conformidade com as ordens estabelecidas. O conceito de crise da consciência, moderno por excelência, supõe, antes, uma cisão no interior do sujeito, ao mesmo tempo em que sugere uma cisão entre o sujeito individual e sua comunidade, cisão que revelaria uma experiência de liberdade, de autonomia, a qual estaria ligada à nova situação social configurada pelas condições modernas da vida e a nascente divisão social do trabalho entre salário e capital.

Todo o início desse processo é descrito por Huizinga (1978, p. 250), em $O$ declínio da idade média, em referência à mudança de referencial, da arte sacra para os retratos de homens e mulheres comuns, pela arte dos países baixos, notadamente de Jan von Eyck. As formas de vida comunitária da Idade média subsistiam sob um conceito substancial (coeso) de razão, conceito cujos suportes, como dissemos, eramlhe exteriores: a autoridade, a tradição, a Igreja. Com o advento do capitalismo (o nascimento das cidades; as grandes navegações e a Reforma protestante, eventos que forjaram novos valores a serem consolidados pelo Iluminismo e pela Revolução Francesa, advindos da crise econômica do feudalismo e da incapacidade do absolutismo de equacionar as pendências religiosas, e outras, de seus súditos $<$ Koselleck, 1999; Engels, 2008; Anderson, 1989>), as formas de vida centradas em comunidades foram, por assim dizer, implodidas, e seus pedaços vieram a constituírem experiências diversas com o tempo (Koselleck, 2006).

Com elas, o conceito de razão que lhes era próprio desapareceu (Huizinga, 1979; Legoff, 2005). A modernidade seria o tempo do reconhecimento do desamparo devido à precariedade das formas de vida disponíveis e o tempo da demanda por uma racionalidade capaz de diminuir aquele desamparo pela superação da precariedade, sob a crença de que a razão seria, mesmo, o instrumento mais capacitado para oferecer a segurança necessária à superação daquela como de outras precariedades: a ação moral e a experiência estética. Tudo quanto merecer permanecer em vida deveria, então, ter assegurada sua justificativa racional, "científica"...

Quando a racionalidade perde seu caráter de substância, de coesão, isto é, 
quando deixa de fazer sentido o conjunto das normas que circundavam as formas de vida comunitária, ganha, por outro lado, azo de formas particulares ou regionais de legitimação (a teórica; a prática e a estética), indicando-se com isso não só uma multiplicidade de campos ou regiões do real, mas também reivindicações múltiplas de justificação, porque cada um desses campos do real apresenta-se cindido (no campo téorico, ciência versus metafísica; no prático, felicidade versus dignidade; no estético, gosto como objeto de discussão versus caráter indiscutível do gosto), demandando assim um esforço de pensamento filosófico que trabalhasse em prol de uma unidade - entretanto - sempre problemática.

A este respeito, em seu ensaio "Materialismo e moral", Max Horkheimer (1990) procura vincular a diferenciação da sociedade (isto é, a multiplicidade das esferas de valor ali destacadas) $e$ o surgimento do indivíduo como sujeito capaz de atribuir-se normas próprias, contrapartida moral da nova situação estética da autonomia da arte. Com efeito, apenas quando os homens começaram a se desfazer das imposições tradicionais e começaram a dar a si mesmos as regras de sua conduta é que os descompassos (possíveis entre a ação e a máxima que a configuraria) começam a provocar aquele tipo de drama a que chamamos crise de consciência, pois ele se vê fazendo exatamente o contrário daquilo que se deu a fazer. Seria a luta entre os impulsos sensíveis, para usar agora uma expressão de Schiller (1990), e as normas da razão.

É a cisão acontecendo no interior do próprio homem. O homem sabe o que é melhor para si e, no entanto, faz o contrário do que sabe (Chauí, 1993). De fato, a experiência histórica posterior desse sujeito veio confirmar que sua liberdade não the dava senão o direito de se tornar uma alavanca numa máquina, de cujo mecanismo ele desconhece qualquer domínio; e é a essa situação de desumanização do homem que se liga aquela "cegueira" própria da arte, ou da autonomização da arte, de que falava Adorno.

\section{III}

Antes, porém, de citar uma vez mais Adorno sobre a situação da arte, que se leia, quanto à situação do indivíduo, essas duas passagens, uma de Olgária Matos; outra, de Horkheimer: "Nas modernas sociedades [...] a individualidade torna-se parte de uma engrenagem cujos mecanismos lhe escapam, o homem não é um fim em si mesmo, uma 'finalidade sem fim', no sentido em que Kant dizia: 'todas as coisas tem um preço, só o homem tem dignidade'. A individualidade é sofredora porque o homem é um meio, um instrumento para a produção e a troca de mercadorias." (Matos, 1997, p. 109). Seu direito de ir e vir, seu direito de alienar-se do senhor feudal, não é usado para a satisfação de sua vida na realização de sua liberdade, mas para não morrer de fome, para a sua sobrevivência, sob as ordens de um novo suserano, o patrão. "Desde o dia do seu nascimento", assim se exprime agora Horkheimer sobre este mesmo assunto, "o indivíduo é levado a sentir que só existe um meio de progredir nesse mundo: desistir de sua esperança de auto realização suprema. Isso ele só pode atingir pela imitação [...]. Através da repetição e imitação das circunstâncias que o rodeiam, da adaptação a todos os grupos poderosos a que eventualmente pertença, da transformação de si mesmo de um ser humano em um membro das organizações, do sacrifício de suas potencialidades em proveito da 
capacidade de adaptar-se e conquistar influência em tais organizações, ele consegue sobreviver. A sua sobrevivência se cumpre pelo mais antigo dos meios biológicos de sobrevivência, isto é, o mimetismo." (Horkheimer, 1976, p. 152) Isto quanto ao indivíduo.

Quanto à questão da arte, que se volte ao texto de Adorno: "A autonomia que ela adquiriu, após se ter desembaraçado da função cultual e dos seus duplos, vivia da ideia de humanidade. Foi abalada na medida em que a sociedade se tornava menos humana. $\mathrm{Na}$ arte, as constituintes que dimanavam do ideal de humanidade estiolaram-se em virtude da lei do próprio movimento" (Adorno, 1982, p. 11). E é a esse movimento que se liga o desenvolvimento da técnica, e notadamente, em termos de história da arte, da técnica de reprodução, que, então, afeta a arte em duas medidas: na medida de sua posição social em face da produção; e na medida de sua recepção.

A reprodutibilidade técnica da obra de arte, pois, contemporânea do auge do indivíduo na experiência das grandes cidades, ao apontar para a destruição da aura da obra autêntica e original, não aponta para um processo de dessacralização no qual o auge da experiência individual seria o momento luciferino onde cada indivíduo seria seu próprio deus (como seria de se esperar), mas para uma dessacralização onde o próprio deus-indivíduo é constantemente profanado em sua dignidade.

Se podemos, de fato, contar a história da arte, seguindo a sugestão de Benjamin, como do processo intensivo de passagem de valor de culto para o valor de exposição, devemos lembrar, com o próprio Benjamin, que "à medida que as obras de arte se emancipam do seu uso ritual, aumenta as ocasiões para que elas sejam expostas." (Benjamin, 1994, p. 173) A exposição, depois da fotografia e do aperfeiçoamento de sua técnica de reprodução, transforma-se, com o cinema, em superexposição. E quanto mais aumenta a exposição, menos sagrada se torna a arte e menos importante o artista. Benjamin ilustra isso, do lado da arte, com a ideia de perfectibilidade infinita da produção cinematográfica, cuja montagem permite o uso de material no sentido de alcançar o cada vez melhor; do lado do artista, o ator de cinema, este é apenas uma peça de um todo, e de um todo que não domina.

Diante disso, parece ser possível lançar um rápido olhar sobre as obras de arte produzidas na época da ascensão do cinema, a chamada arte de vanguarda, e indagar, no desespero da perda de importância em que a arte dita original foi colocada, se aquela característica central dessa arte, a crise da representação, a perda da referência, não seria um último e salvador gesto da mímesis, no sentido de imitar uma volta à caverna, a caverna agora dentro do próprio quadro, da própria música serial, da própria poesia hermética, a fim de, no centro da superexposição, atentar-se para uma última chance de dignidade...

De fato, Benjamin dá a dica dessa leitura possível, quando sugere uma sociologia da art pour l'art dizendo que seria um último refúgio do valor de culto em um mundo onde só existe a chance de valer o que multiplamente se expõe. O afrouxamento do controle religioso sobre a arte seria a contrapartida exata da própria perda do caráter religioso da arte. Tudo se passa como se, podendo-se atingir o controle social por outros meios que o religioso (Thompson, 2011), a arte fosse liberada de sua função religiosa, ao mesmo tempo em que o indivíduo, emancipado da religião em meio à metrópole (Bürger, 2017, p. 162), sofria sua libertação social como um fardo, um infortúnio, um grande ludibrio (Hirschman, 2002), pois ser livre do senhor feudal implicava agora, não só ter de procurar para si um sentido, como 
ainda ter de viver sem um, retido horas sem fim nas minas de carvão, nas fábricas insalubres, entre máquinas ensurdecedoras e, por fim, deixar-se ficar preso nas malhas invisíveis da ilusão liberal segundo a qual se é um indivíduo livre, quando aquilo que constitui o mais íntimo de si, a força de trabalho, permanece sendo apenas uma mercadoria, uma mercadoria usada a bel prazer por outrem, que a compre.

Voltar à caverna na própria obra, fazer da obra uma caverna particular, eis uma forma de trazer de volta à arte seu poder de delírio e de mistério; trazer de volta para o artista o "poder" - que a magia, nos primórdios, lhe assegurava, isto é, que a totalidade viva do povo, mantida viva na crença dos sortilégios mágicos da arte, concedia ao artista - para seu próprio benefício... uma vez que a valorização do membro da tribo nunca é um processo de produção de indivíduos emancipados, senão que - paradoxo - forma de reforçar a unidade coesiva da própria coletividade.

Referências

ADORNO, TH. Teoria estética. Trad.: A. Morão. Lisboa: Edições 70, 1983.

ANDERSON, P. Linhagens do estado absolutista. São Paulo: Brasiliense, 1989.

ANDRADE, A. C. Fragmento como forma. A filosofia na experiência da modernidade. São Paulo: Opção, 2016.

ARRIÈS, PH. e DUBY, G. História da vida privada. São Paulo: Companhia de Bolso, 2009.

AUBOYEUR, J. e AYMARD, A. História geral das civilizações, v. 2. Trad.: P. M. Campos. Rio de Janeiro: Bertrand do Brasil, 1993a.

AUBOYEUR, J. e AYMARD, A. História geral das civilizações, v. 2. Trad.: P. M. Campos. Rio de Janeiro: Bertrand do Brasil, 1993b.

BENJAMIN, W. Obras escolhidas, v. I. Trad.: S. P. Rouanet. São Paulo: Brasiliense, 1994.

BÜRGER, P. Teoria da vanguarda.Trad.: J. P. Antunes. São Paulo: Ubu, 2017.

CHAUÍ, M. "Servidão e liberdade na ética IV", in: Discurso, n. 22, FFLCH- USP, 1993.

DUMONT, L. O individualismo. Trad.: A. Cabral. Rio de Janeiro: Rocco, 2000.

ENGELS, F. "As revoltas camponesas na Alemanha", in: A revolução antes da revolução, v. I. Trad.: C. Jardim. São Paulo: Expressão Popular, 2008.

HABERMAS, J. O discurso filosófico da modernidade. Trad.: L. Repa e R. Nascimento. São Paulo: Martins Fontes, 2000.

HIRSCHMAN, A. O. As paixões e os interesses. Argumentos políticos a favor do capitalismo antes de seu triunfo. Trad.: L. G. Chaves e R. Bhering. Rio de Janeiro: Record, 2002.

HORKHEIMER, M. "Materialismo e moral”, in: Teoria Crítica I. São Paulo: Perspectiva, 1990.

HORKHEIMER, M. "Ascensão e declínio do indivíduo", in: Eclipse da razão. Rio de Janeiro: Labor do Brasil, 1976.

KOSELLECK, R. Crítica e crise: uma contribuição à patogênese do mundo burguês. Rio de Janeiro: Eduerj, 1999.

KOSELLECK, R. Futuro passado. Contribuição à semântica dos tempos históricos. Trad.: W. P. Mass e C. A. Pereira. Rio de Janeiro: Contraponto, 2006.

HUIZINGA, J. O declínio da idade média. Trad.: A. Abelaira. São Paulo: Verbo-Edusp, 1978.

LEBRUN, G. A filosofia e sua história. Org.: C. A. R. de Moura; M. L. M. O. Cacciola; M. Kawano. São Paulo: Cosac Naify, 2006.

LEGOFF, J. A civilização do ocidente medieval. Trad.: J. R. de Macedo. Bauru-SP: Edusc, 2005.

MARRAMO, G. Poder e secularização. São Paulo: Unesp, 1995.

MATOS, O. Os arcanos do inteiramente outro. São Paulo: Brasiliense, 1989.

MATOS, O. História viajante. São Paulo: Studio Nobel, 1997.

SCHILLER, F. A educação estética do homem. São Paulo: Iluminuras, 1990.

THOMPSON, E. O. A formação da classe operária inglesa. A árvore da liberdade. São Paulo: Paz \& Terra, 2011.

VOEGELIN, E. Ordem e história, v. I. Israel e a revelação. Trad.: C. C. Bartolotti. São Paulo: Loyola, 2009. 